\title{
Comparative analysis of strength and crack resistance of normal sections of bent elements of T-sections, made of rubber concrete, kauton reinforcement and concrete
}

\author{
Yuriy Potapov ${ }^{1}$, Alexey Polikutin ${ }^{1 *}$, Dmitry Panfilov ${ }^{1}$, and Mikhail Okunev ${ }^{1}$ \\ ${ }^{1}$ Voronezh State University of Architecture and Civil Engineering. 20-letiya Oktayabrya Str., 84, \\ 394006, Voronezh, Russia,
}

\begin{abstract}
One of the urgent tasks of development of the construction associated with the development of new building designs, the use of which provides increased strength, crack resistance, reducing the flow of construction materials, reducing the labor intensity, energy consumption and cost. Ensuring effective functioning of structures during their operation in the harsh environments associated not only with the task of developing materials of higher strength and corrosion resistance, but also composites of increased strength and crack resistance, as structural materials crack resistance is largely determined by the ability of the structure to prevent the formation and growth of cracks. For structures operating in conditions of chemical action, the question of crack resistance is paramount, as the disclosure of cracks in aggressive environment, penetrating deep into the section and causing corrosion of the reinforcement will significantly impair the ability of the load bearing capacity of the element as a whole. The results of experiments of polymer concrete beams of the cross T-profile and comparison of the results with those obtained in an experiment similar to concrete and kauton reinforced elements are given. The observations of the stress-strain state of polymer concrete of flexural members, strength and crack resistance of these elements are presented.
\end{abstract}

\section{Introduction}

Creation on the basis of polybutadiene oligomer belonging to the class of liquid polymers, composite materials of new generation, reinforced longitudinal rod reinforcement - kauton reinforcement with high chemical resistance, crack resistance, strength and other favorable conditions is a promising direction in the solution of this issue. In practice, wide application of polymer concrete based on furan, epoxy, polyester, urea-formaldehyde and other resins

Corresponding author: apl-sc@mail.ru 
is seen in construction. However, industrial production of these resins in Russia in recent years has declined sharply, and was completely outside the territory of the country (furan resin), therefore bringing their cost to have risen sharply and close to world prices. In this situation, issues related to the protection of building structures from the aggressive effects of the environment are possible with the use of alternative types of commercially available polymers, for example, diene oligomers, belonging to the class of liquid polymers. Obtained on the basis of liquid polymers produced at the Voronezh industry is Synthetic Rubber (SC-2), the material - polymer concrete, has in addition to the favorable physical and mechanical properties and high chemical resistance and can, together with effective species of polymer concrete take its place at the decision for protection against corrosion problems of various products and structures operating in aggressive environments. In addition, the introduction of a mixture of polymer concrete of large technogenic waste allows to solve the environmental problem associated with their disposal. Creating a safe and efficient working flexural member is impossible without studying the stress-strain state, which occurs when exposed to different kinds of forces.

In the course of studies of the properties of rubber concrete and building structures based on it, was worked by: Borisov Yu.M. [1,2,3,4,5], Potapov Yu.B [6,7], Polikutin A.E. [8], Figovsky O.V. [9], Nguyen Phan Duy [10], Pinaev S.A. [11], Chmykhov V.A. [12] etc., the effectiveness of this material and designs based on it has been proven.

\section{Experimental studies}

The work is devoted to the experimental study of strength and crack resistance of normal sections of polymer concrete of flexural members of T-section with a shelf made of concrete and the wall made of polymer concrete at cross bending under the influence of short-term loads, and the comparison of their work with that of similar kauton reinforcement and reinforced-concrete flexural members of T-section.

To solve the problems we need to produce a series of samples of polymer concrete of flexural members of T-cross-section (Fig. 1).
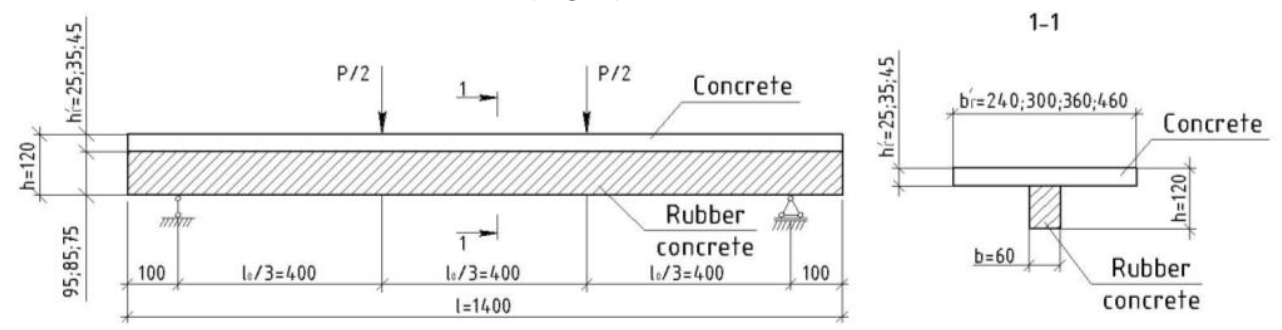

Fig. 1. General view and the diagram of the experimental load beams

The main variable parameters are proposed as follows: the height of the concrete flange $\mathrm{hf} /$, flange width bf/ and percentage of longitudinal reinforcement $\mu$. For comparison of work of polymer concrete of flexural members of $\mathrm{T}$ cross-section with the work of singlelayered reinforced concrete flexural members and kauton reinforcement of cross $\mathrm{T}$ profile, we need to produce a similar series of concrete beams and kauton reinforcement with dimensions similar to the dimensions in (Fig. 1), and with the same variable parameters. All samples were tested for transverse beams two bending symmetrically arranged acting forces in the thirds of the span (Fig. 1). All field tests of the control samples and experimental beams were carried out in the center of collective use named after Professor Yu.M. Borisov at the Voronezh GASU. 

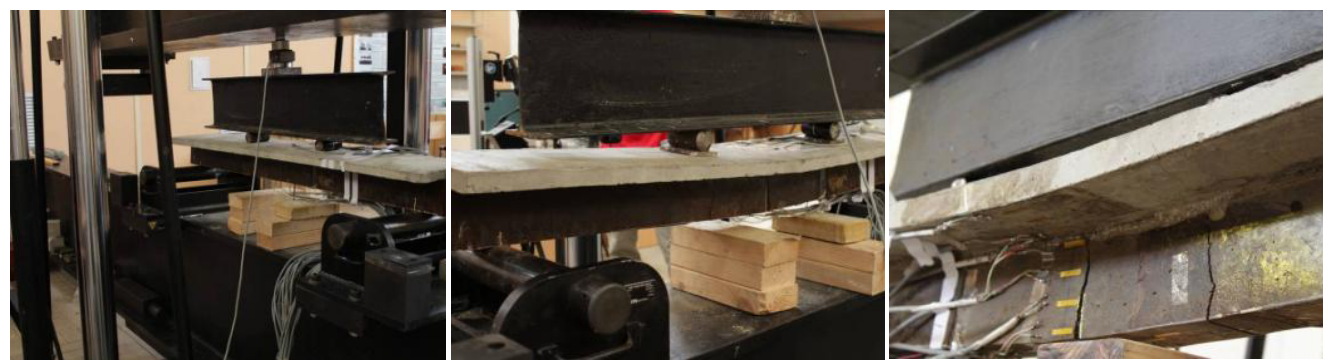

Fig. 2. Experimental beam before and after the experiment

To get a clear picture of the stress-strain state of normal sections of double-layered polymer concrete of flexural member,the longitudinal deformation section height was measured by the means of strain gauges glued on the height of the section at mid-span (Fig. $3)$.

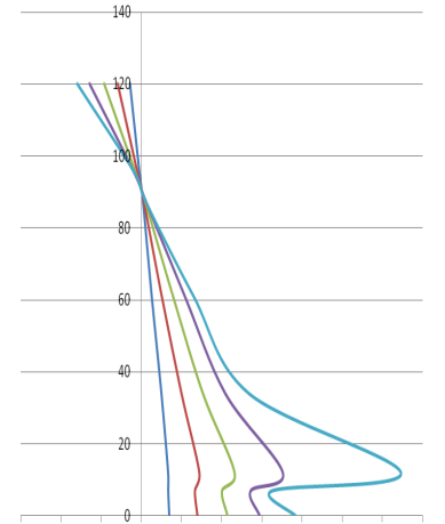

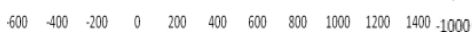
$1 \mathrm{C}-8 \mathrm{~KB}-25-240$
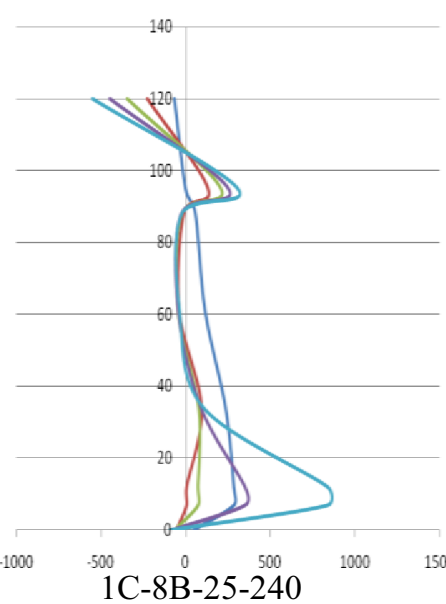

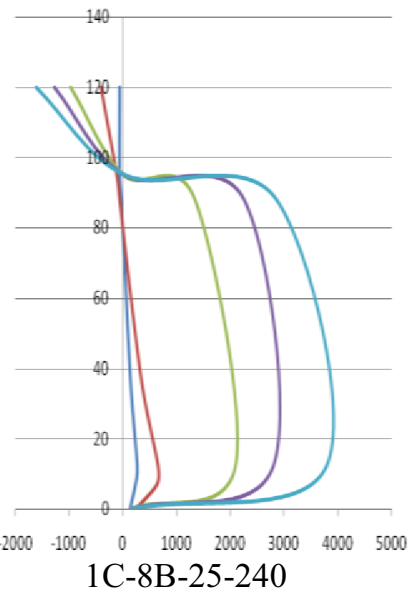

$1 \mathrm{C}-8 \mathrm{~B}-25-240$

Fig. 3. Schedule the distribution of deformation height of the normal section beams

In order to move from strain to the stress, the relationship " $\sigma_{b}-\varepsilon_{b}$ "is used in the concrete to determine compression and tension, resulting in a experiment of concrete test samples. For polymer concrete, the relationship " $\sigma_{k}-\varepsilon_{k}$ " is used on the compression and tension, as obtained in the test control samples of polymer concrete.

Analysis of test results allowed to establish the nature of the distribution of the longitudinal strain at the height of the cross section in the zone of pure bending. Changes in strain and stress adjustment section under the influence of an external load are shown in Fig. 4. 


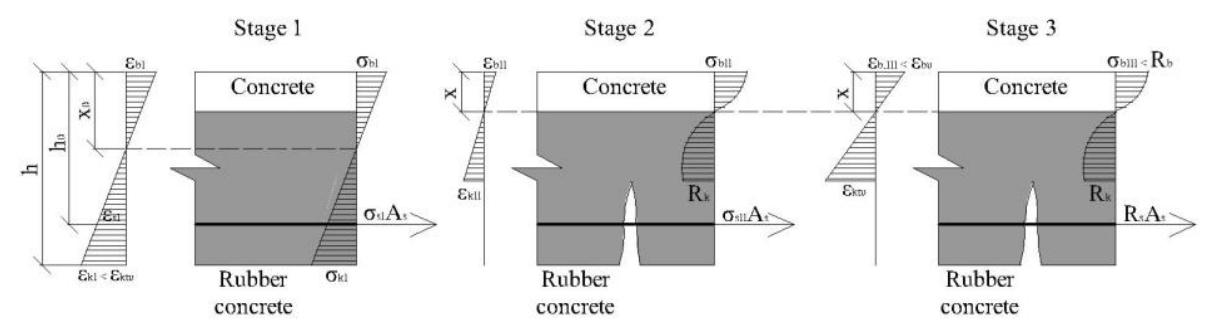

Fig. 4. Stages of stress-strain state of the normal section of double-layered rubber concrete of bent elements of T-sections

$\varepsilon_{b, I}, \varepsilon_{b, I I}, \varepsilon_{b, I I I}$ и $\sigma_{b, I}, \sigma_{b, I I}, \sigma_{b, I I I}$ - respective strains and stresses in the extreme fibers of compressed concrete in stages 1, 2, 3;

$R_{b}$ - the compressive strength of concrete;

$\sigma_{s, I}, \sigma_{s, I I}-$ respective fitting of the tensile stress in stages 1, 2;

$R_{k t}$ - strength in tension of rubber concrete;

$R_{s}$ - tensile strength reinforcement in tension;

$A_{s}$ - the cross-sectional area of the valve.

Analyzing the dependence of the stresses on the sectional height of the load, it can be concluded that the normal section at mid-span of double-layered polymer concrete of flexural members undergoes 3 stages of stress-strain state.

Stage 1 - before the appearance of cracks to the normal of polymer concrete. Until the moment of the formation of cracks to the normal of polymer concrete, the deformation of compression and tensile strain is distributed linearly. In this stage, the stress in the compression zone of the concrete, polymer concrete and fittings is small, deformations are predominantly elastic in nature and the strains and stresses have a linear relationship. Prior to the formation of cracks in polymer concrete the deformation values of the stretched fiber of polymer concrete reach the limit. With further increase in load comes a new qualitative state of structural work.

Stage 2 - after the appearance of normal cracks in the polymer concrete. At this stage, there is a significant redistribution of stresses in normal sections. In these tensile areas where cracks are formed, tensile forces undergo reinforcement. In the intervals between the cracks in the tension zone the contact of the reinforcement with the polymer concrete is preserved and the distance from the edges of the cracks, the tensile forces in polymer concrete increases and decreases in the reinforcement. With further increase, the loads in the concrete of the compression zone increases inelastic deformation, stress diagram in a compressed zone is curved. Upper compression deformation fibers increases, but still have not reached the limit values. At this stage part of the concrete at the tensile zone (above the top of the crack) continues to resist external load and accept tensile forces. Here, there is formation of new and increase in the existing cracks. The height of the compressed zone is significantly reduced (Table 2).

Stage 3 - just before the destruction of the element. At this stage there are inelastic deformations in the concrete at the compressed zone, compressive stresses become curvilinear. The height of the compressed zone is significantly reduced. With a weak reinforcement, stresses in reinforcement reach the yield limit, stresses in the concrete at the compressed zone under the influence of the deflection element and reduction in the height of the compressed zone reach the values of temporary resistance to compression. Destruction of polymer concrete element starts from the reinforcement at tensile zone. 
In this case, the work of normal sections of double-layered polymer concrete of flexural members is similar to the work of normal sections of single-layered reinforced concrete of flexural members.

As shown by the studies, the effective factor in the strength of the normal sections of double-layered polymer concrete of bending elements is the percentage of longitudinal reinforcement.

The graphs of relative deformations of the loads of some beams are shown in Fig. 5.

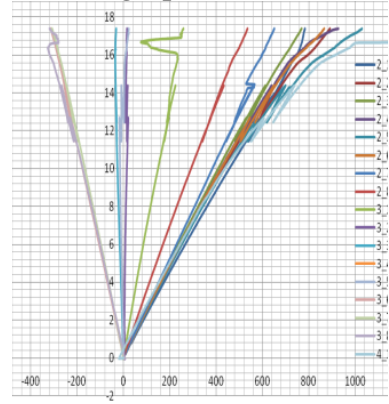

$1 \mathrm{C}-8 \mathrm{~KB}-25-240$

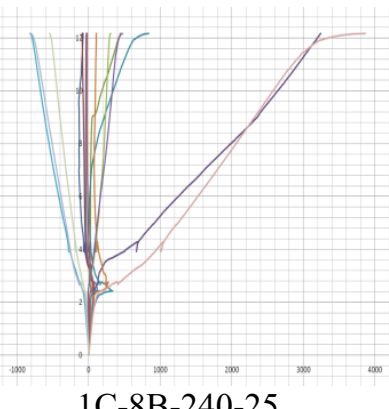

$1 \mathrm{C}-8 \mathrm{~B}-240-25$

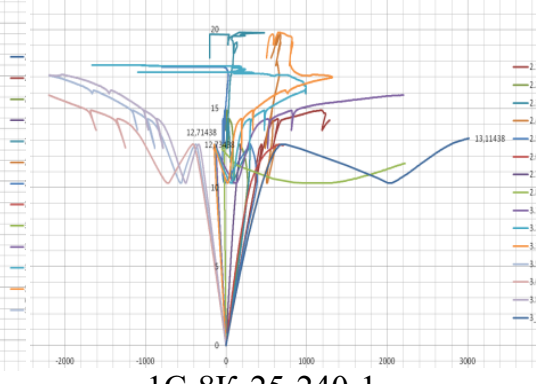

$1 \mathrm{C}-8 \mathrm{~K}-25-240-1$

Fig. 5. The graphs of relative deformations of the external loads for experimental beams

After analysis, the realized values of the bending moments in the destruction of elements (time flow valve) are summarized in Table 1.

Table 1. - Bending Test Results

\begin{tabular}{|c|c|c|}
\hline $\begin{array}{c}\text { Reference } \\
\text { designation }\end{array}$ & $\begin{array}{c}\text { The percent of } \\
\text { longitudinal } \\
\text { reinforcement } \mu,[\%]\end{array}$ & $\begin{array}{c}\text { The bending moment of the destruction of } \\
\text { the sample (at fluxion of reinforcement), } \\
\mathrm{M}_{\mathrm{p},}\left[\mathrm{KH} \mathrm{H}^{*}\right]\end{array}$ \\
\hline KB_8 & 0.84 & 3.506 \\
\hline KB_12 & 1.89 & 6.540 \\
\hline KB_16 & 3.35 & 9.811 \\
\hline K_8 & 0.84 & 2.798 \\
\hline K_12 & 1.89 & 6.996 \\
\hline K_16 & 3.35 & 10.376 \\
\hline B_8 & 0.84 & 2.436 \\
\hline B_12 & 1.89 & 6.116 \\
\hline B_16 & 3.35 & 9.376 \\
\hline
\end{tabular}

The test results of two-layered rubber concrete, single-layered kauton reinforcement and reinforced-concrete of bent elements of T-sections are presented in Table 2. 
Table 2. Test results of bent elements of T-sections, made of rubber concrete, kauton reinforcement and concrete.

\begin{tabular}{|c|c|c|c|c|c|c|c|c|}
\hline The beam codes & $\begin{array}{c}\mu, \\
{[\%]}\end{array}$ & $\begin{array}{c}\mathrm{x} \\
{[\mathrm{mm}]}\end{array}$ & $\begin{array}{c}\mathrm{M}_{\mathrm{u}}, \\
{[\mathrm{KN} \cdot \mathrm{m}]}\end{array}$ & $\varepsilon_{\mathrm{kt}} \cdot 10^{3}$ & $\varepsilon_{\mathrm{ktk}} \cdot 10^{3}$ & $\begin{array}{c}\mathrm{R}_{\mathrm{b}} \\
{[\mathrm{MPa}]}\end{array}$ & $\begin{array}{c}\mathrm{R}_{\mathrm{k}}, \\
{[\mathrm{MPa}]}\end{array}$ & $\begin{array}{c}\mathrm{R}_{\mathrm{kt}} \\
{[\mathrm{MPa}]}\end{array}$ \\
\hline $\begin{array}{l}1(2,3) \mathrm{C}-8 \mathrm{~KB}-25- \\
240-1 .\end{array}$ & 0,84 & 23.7 & 3.51 & 0.60 & 0.59 & 33.10 & 85.50 & 10.90 \\
\hline $\begin{array}{l}1(2,3) \mathrm{C}-10 \mathrm{~KB}-25- \\
240-1\end{array}$ & 1.31 & 24.4 & 5.13 & 0.64 & 0.62 & 32.45 & 82.90 & 12.40 \\
\hline $\begin{array}{l}1(2,3) \mathrm{C}-12 \mathrm{~KB}-25- \\
240-1\end{array}$ & 1.89 & 25.4 & 6.54 & 0.67 & 0.65 & 31.80 & 80.30 & 13.90 \\
\hline $\begin{array}{l}1(2,3) \mathrm{C}-14 \mathrm{~KB}-25- \\
240-1 .\end{array}$ & 2.57 & 25.4 & 8.46 & 0.71 & 0.69 & 32.15 & 80.80 & 13.15 \\
\hline $\begin{array}{l}1(2,3) \mathrm{C}-16 \mathrm{~KB}-25- \\
240-1\end{array}$ & 3.35 & 26.2 & 9.81 & 0.74 & 0.73 & 32.50 & 81.30 & 12.40 \\
\hline $\begin{array}{l}1(2,3) \mathrm{C}-8 \mathrm{~B}-25-240- \\
1 .\end{array}$ & 0,84 & 18.1 & 2.43 & - & - & 32.65 & - & - \\
\hline $\begin{array}{l}1(2,3) \mathrm{C}-10 \mathrm{~B}-25- \\
240-1\end{array}$ & 1.31 & 19.4 & 4.28 & - & - & 31.68 & - & - \\
\hline $\begin{array}{l}1(2,3) \mathrm{C}-12 \mathrm{~B}-25- \\
240-1\end{array}$ & 1.89 & 20.4 & 6.12 & - & - & 30.70 & - & - \\
\hline $\begin{array}{l}1(2,3) \mathrm{C}-14 \mathrm{~B}-25- \\
240-1 .\end{array}$ & 2.57 & 20.5 & 7.96 & - & - & 31.75 & - & - \\
\hline $\begin{array}{l}\text { 1(2,3)C-16B-25- } \\
240-1 \text {. }\end{array}$ & 3.35 & 20.9 & 9.38 & - & - & 32.80 & - & - \\
\hline $\begin{array}{l}1(2,3) \mathrm{C}-8 \mathrm{~K}-25-240- \\
1 .\end{array}$ & 0,84 & 21.4 & 2.80 & 0.78 & 0.75 & 32.50 & 84.00 & 9.20 \\
\hline $\begin{array}{l}1(2,3) \mathrm{C}-10 \mathrm{~K}-25- \\
240-1\end{array}$ & 1.31 & 22.6 & 5.47 & 0.69 & 0.66 & 32.25 & 84.45 & 11.75 \\
\hline $\begin{array}{l}1(2,3) \mathrm{C}-12 \mathrm{~K}-25- \\
240-1 .\end{array}$ & 1.89 & 25.0 & 6.99 & 0.59 & 0.57 & 32.00 & 84.90 & 14.30 \\
\hline $\begin{array}{l}1(2,3) \mathrm{C}-14 \mathrm{~K}-25- \\
240-1 .\end{array}$ & 2.57 & 25.3 & 9.29 & 0.66 & 0.60 & 31.65 & 84.20 & 12.85 \\
\hline $\begin{array}{l}1(2,3) \mathrm{C}-16 \mathrm{~K}-25- \\
240-1\end{array}$ & 3.35 & 25.5 & 10.38 & 0.72 & 0.63 & 31.30 & 83.50 & 11.40 \\
\hline
\end{tabular}

$\mu$ - the percentage of longitudinal reinforcement;

$x$ - the height of the compressed zone before destruction;

$M_{u}$ - breaking bending moment;

$\varepsilon_{k t}-$ rubber concrete deformation in the test samples on tension;

$\varepsilon_{k t k}$ - extreme fiber deformation of rubber concrete at the stretched zone during the priod of crack formation;

$R_{b}$ - prism strength of concrete;

$R_{k}$ - prism strength of rubber concrete;

$R_{k t}$ - rubber concrete strength in tension.

The dependence in strength of the bending kauton reinforced, polymer concrete and concrete elements on the percentage of longitudinal reinforcement is shown in Fig. 6. 


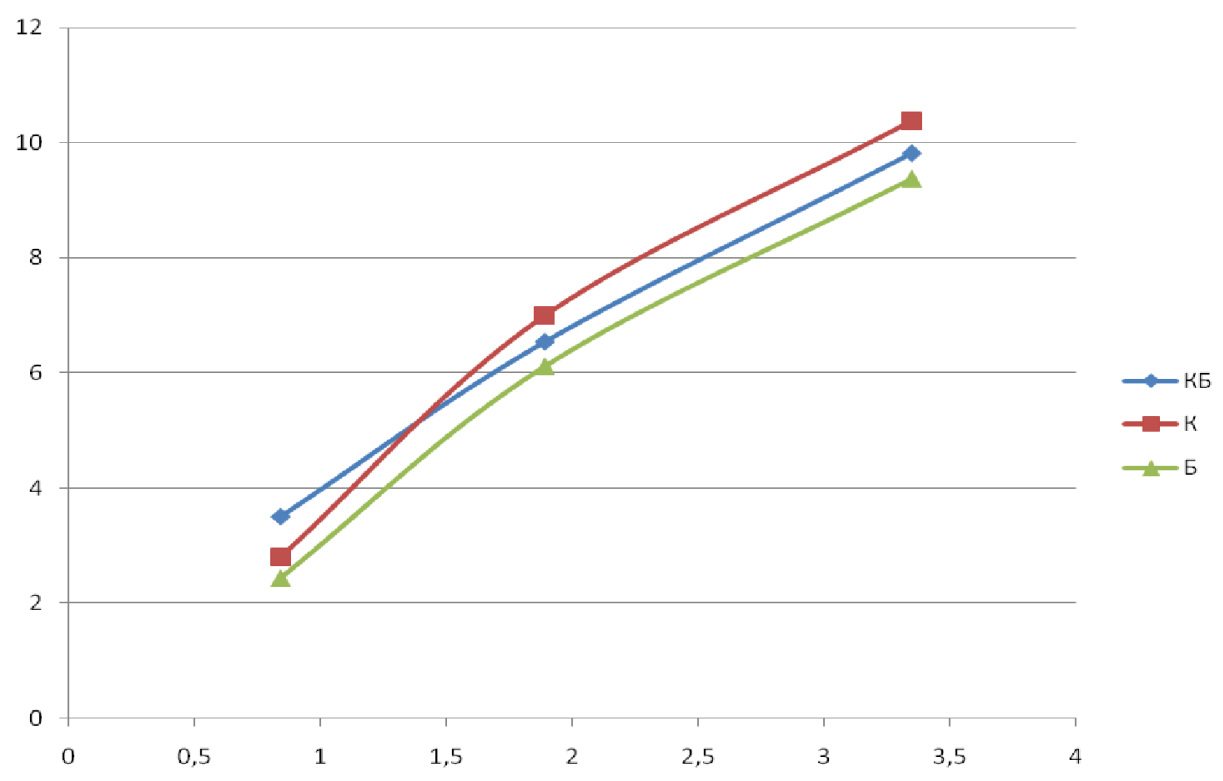

Fig. 6. The graph of dependence of the strength of the flexural members of kauton-concrete, kauton reinforcement, concrete on the percentage of longitudinal reinforcement

An analysis of the graph in Fig. 6 shows that the strength of the flexural members of kauton reinforcement, polymer concrete and concrete increases with increasing percentage of the longitudinal reinforcement. By increasing the percentage of longitudinal reinforcement from $0.84 \%$ to $3.35 \%$ the strength of normal sections of polymer concrete beams increases almost linearly.

The load bearing capacity of structures in the tension zone of polymer concrete is higher than those of reinforced concrete structures and this is due to the fact that the high grip of reinforcement and rubber concrete prevents rapid development of plastic deformation in the reinforcement, as well as part of polymer concrete around the tension zone between the cracks involved in construction as a whole.

It is pertinent to note that for a small percentage of reinforcement, polymer concrete beam collapses at a higher load than polymer reinforcement, but with an increase in interest of load bearing capacity kauton reinforcement of reinforcing elements becomes greater than polymer concrete by $5.4-6.5 \%$.

On these assumptions at the time of cracking an abrupt increase in strain is noted. The value of the bending moment corresponding to the point of the hop deformation, is the moment of the formation of cracks in the polymer concrete.

Cracking moments of normal sections of double-layered polymer concrete of bent flexural members of T-sections, depending on the percentage of longitudinal reinforcement and comparison with the cracking moments of normal sections of reinforced concrete and kauton reinforcement of flexural members are shown in Fig. 7. 


\section{TPACEE-2016}

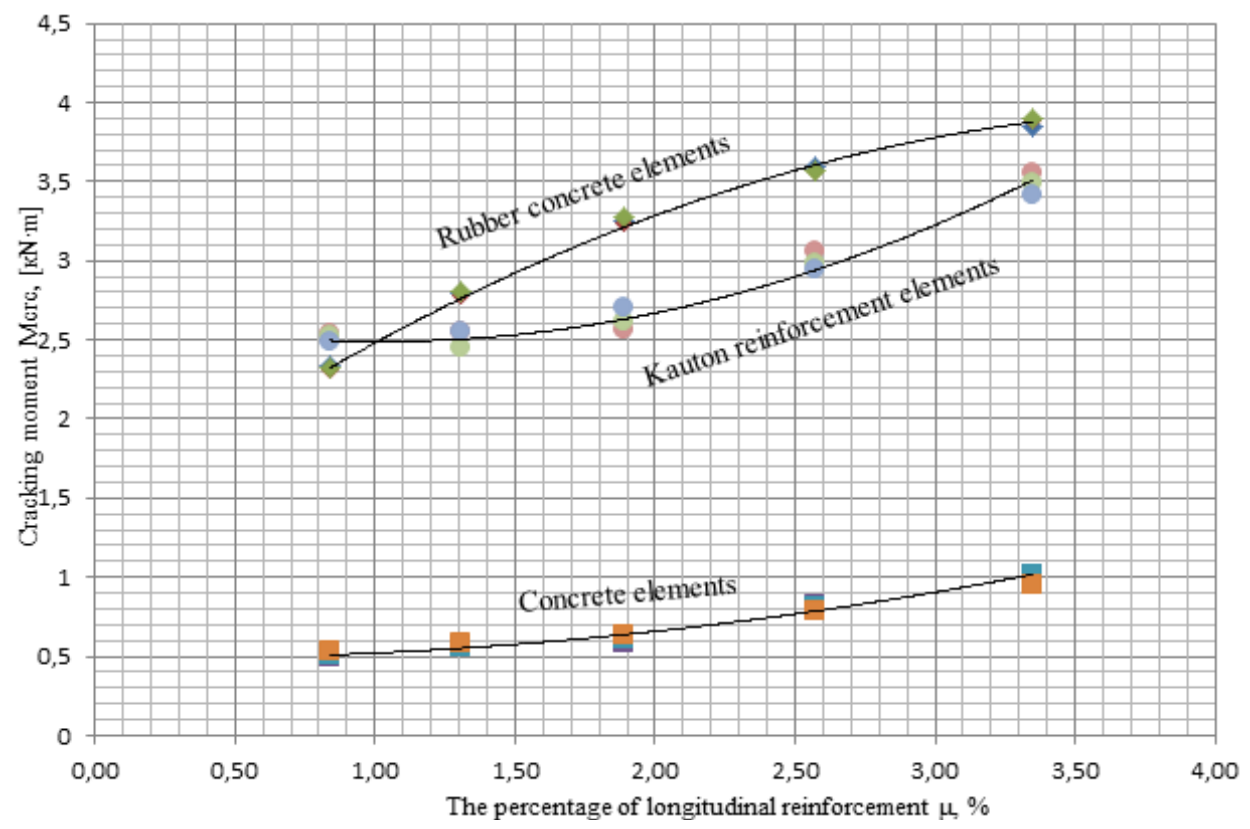

Fig. 7. Cracking moments of experimental beams, in relation to the percentage of longitudinal reinforcement

The testing results of two-layer rubber concrete, single-walled reinforced concrete bent elements and armorubber concrete and analysis revealed that fracture rubber concrete samples is significantly higher than the concrete (average 78.05\%). Crack resistance rubber concrete samples higher than armorubber concrete (average 12.78\%), but a small percentage of longitudinal reinforcement $(\mu=0,84 \%)$ samples from armorubber concrete showed the best evidence of fracture toughness than rubber concrete (at $9.96 \%$ ).

The tests allowed to identify three stages of the formation of cracks in the normal bilayer rubber concrete bent elements of T-sections.

First stage. Disrupted strain distribution patterns in rubber concrete - strain in those sections where further cracks, increase the intensity compared to neighboring.

Second stage. The formation of cracks in these sections. This deformation in the reinforcement and the extreme fiber tensile verge abruptly increased. The height of the compressed zone is significantly reduced.

Third stage. When the load growth cracks develop on the sectional height. This continues the cracking in adjacent sections until the destruction of the element. 


\section{TPACEE-2016}

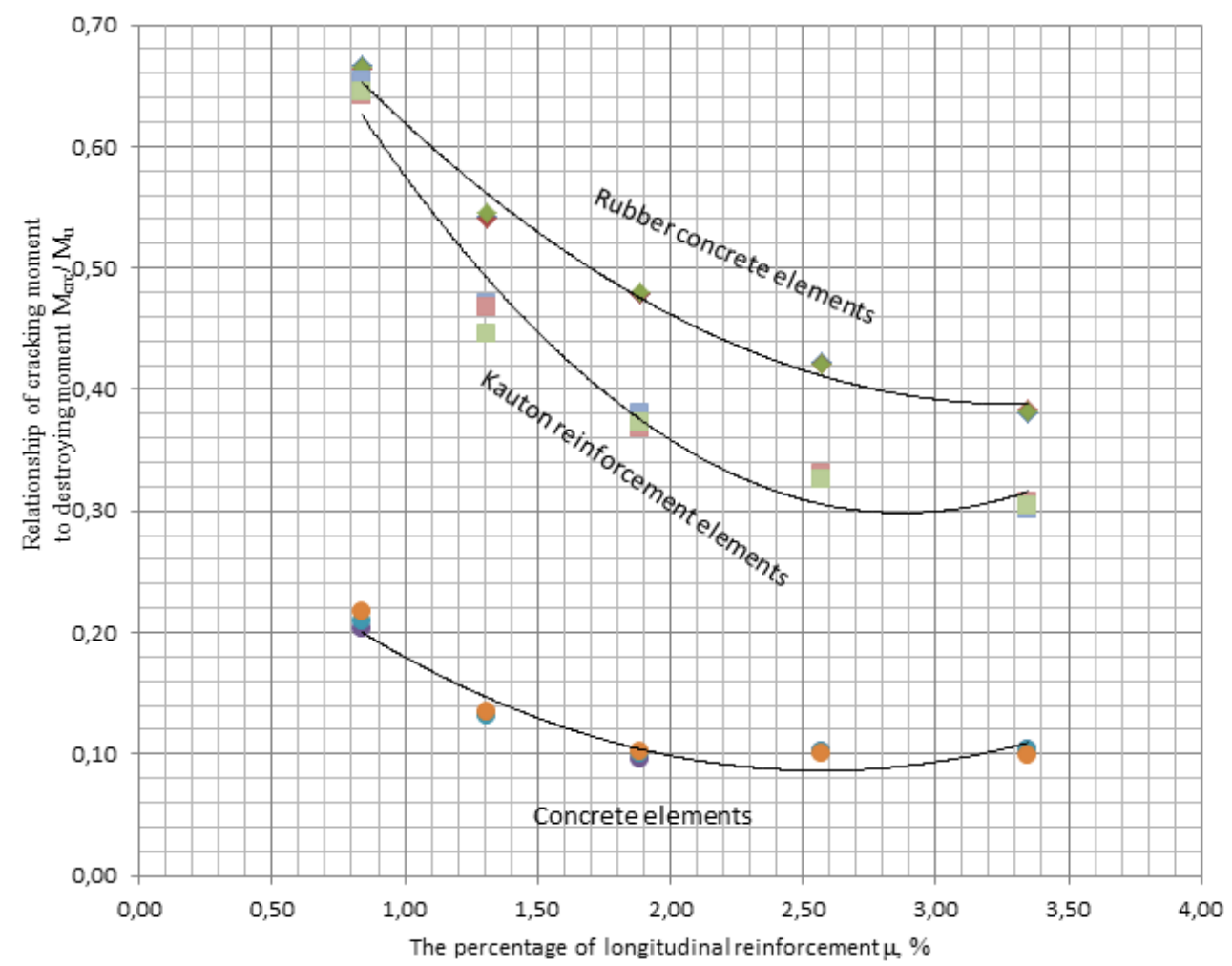

Fig. 8. Dependence of the relationship of cracking moments to breaking moments of the experimental elements of T-sections on the percentage of longitudinal reinforcement

The experimental results show that with the increase in the percentage of longitudinal reinforcement, the effect of raising the crack resistance decreases (Fig. 8). This is due to the fact that in a high percentage of reinforcement, significant part of force at the time of cracking experienced reinforcement and only a small proportion of the load acts on polymer concrete.

The results for the determination of the width of cracks to the normal to the longitudinal axis of the elements, depending on the ratio of the acting cracks to the breaking of the bending moments are shown in Fig. 9-13. 


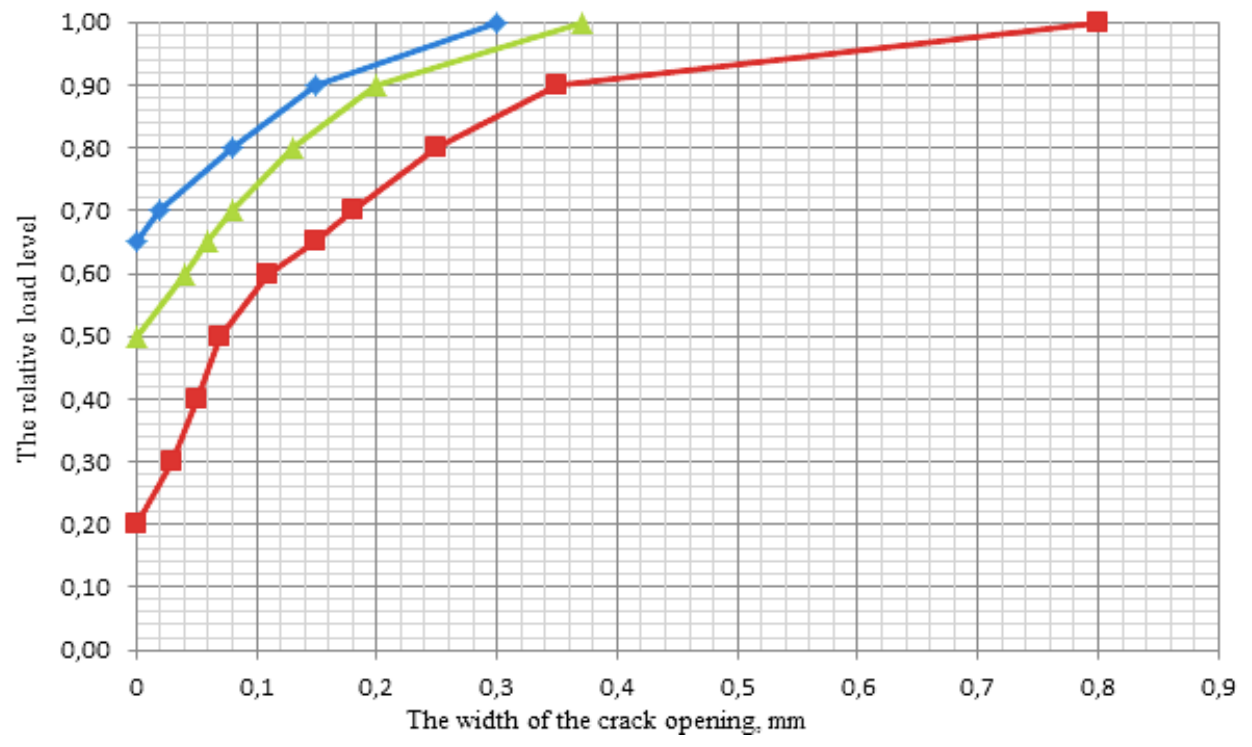

Fig. 9. The width of cracks in beams with the percentage of longitudinal reinforcement $\mu=0,84 \%$

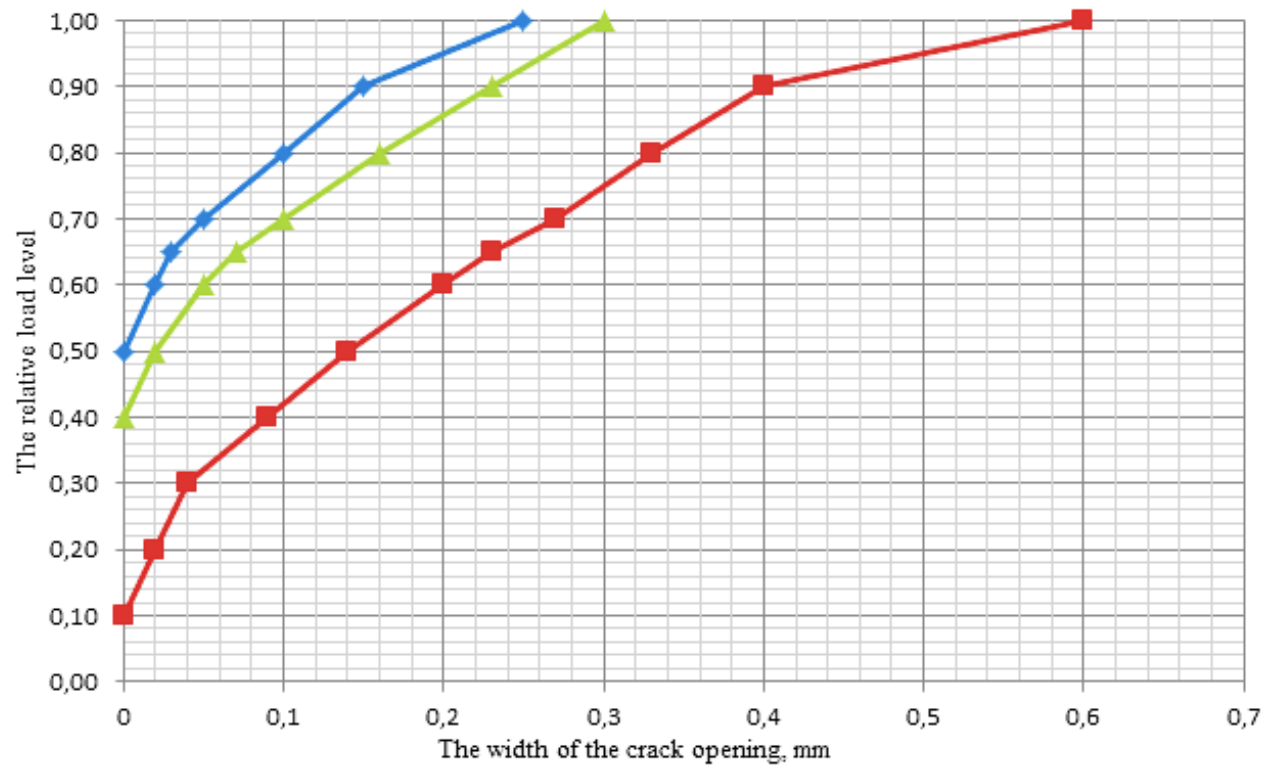

Fig. 10. The width of cracks in beams with the percentage of longitudinal reinforcement $\mu=1,31 \%$ 


\section{TPACEE-2016}

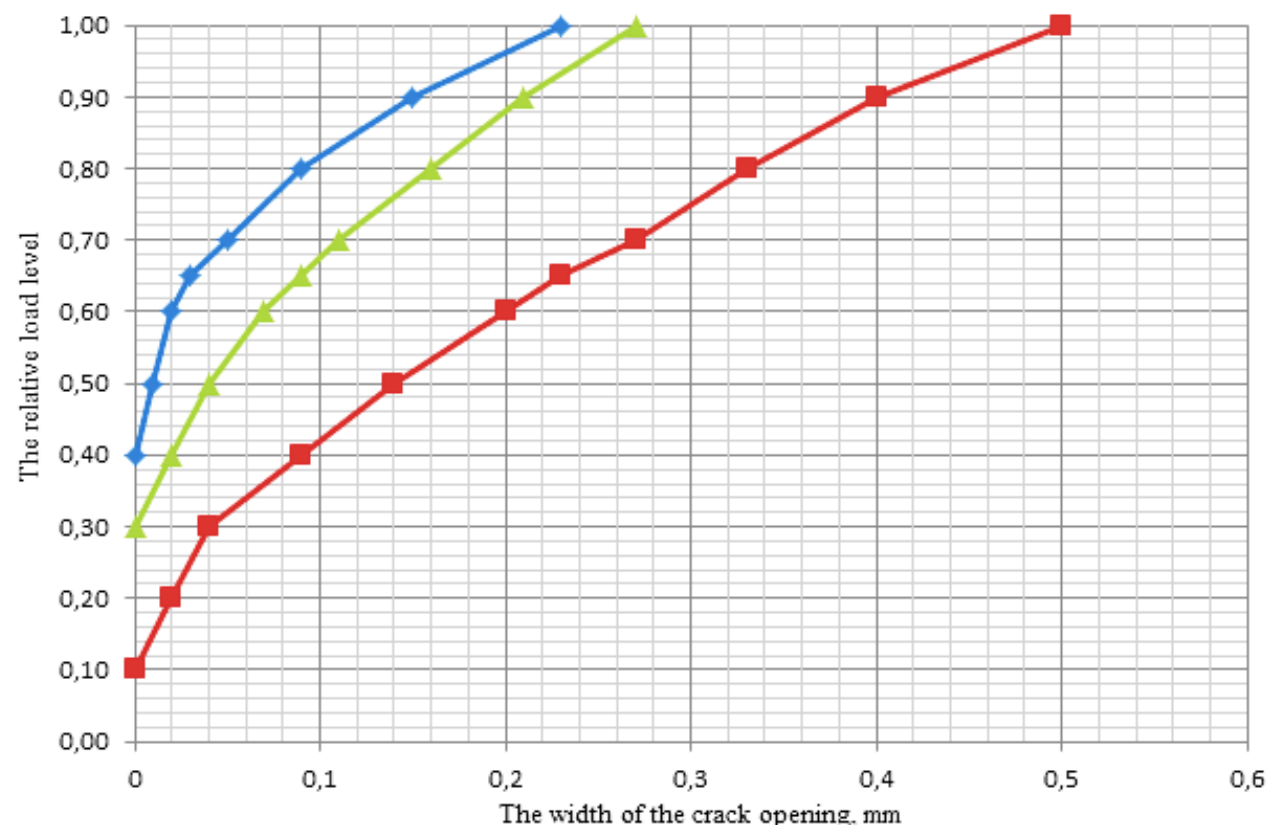

Fig. 11. The width of cracks in beams with the percentage of longitudinal reinforcement $\mu=1,89 \%$

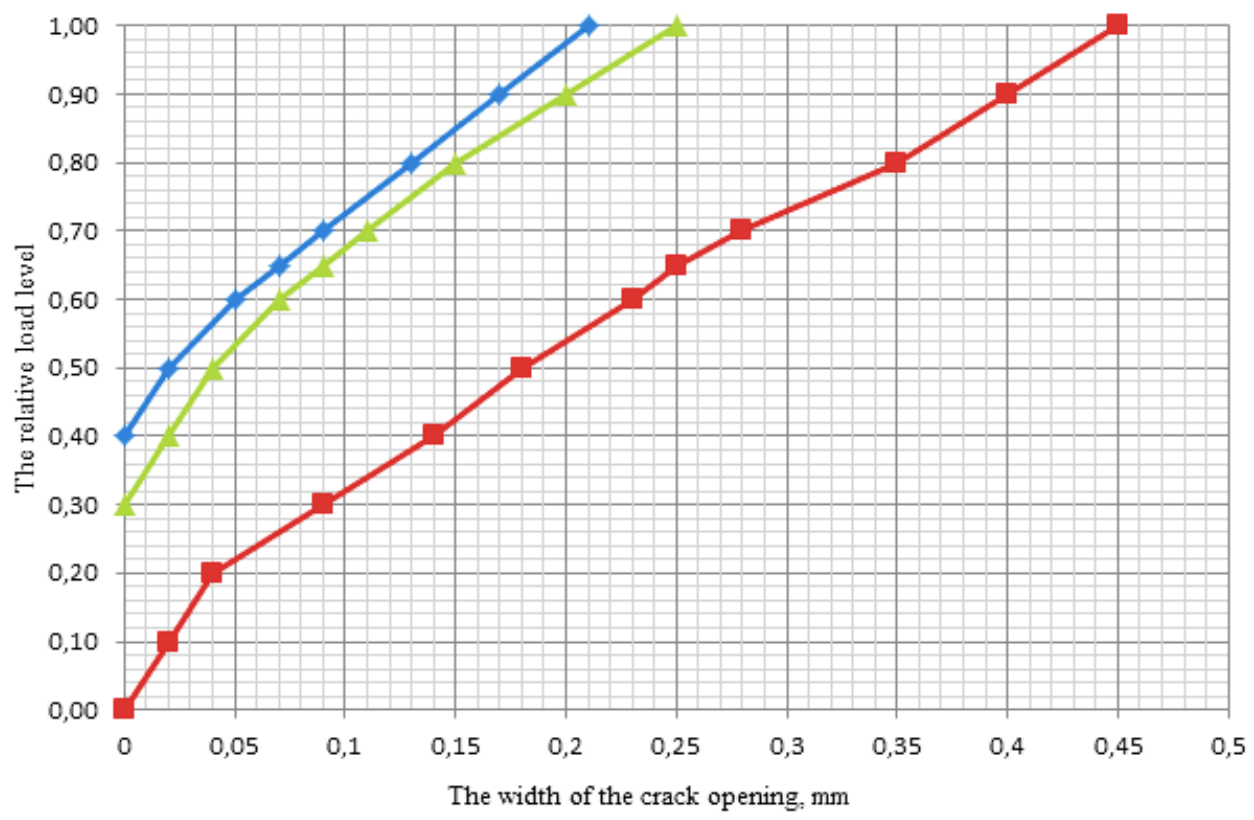

Fig. 12. The width of cracks in beams with the percentage of longitudinal reinforcement $\mu=2,57 \%$ 


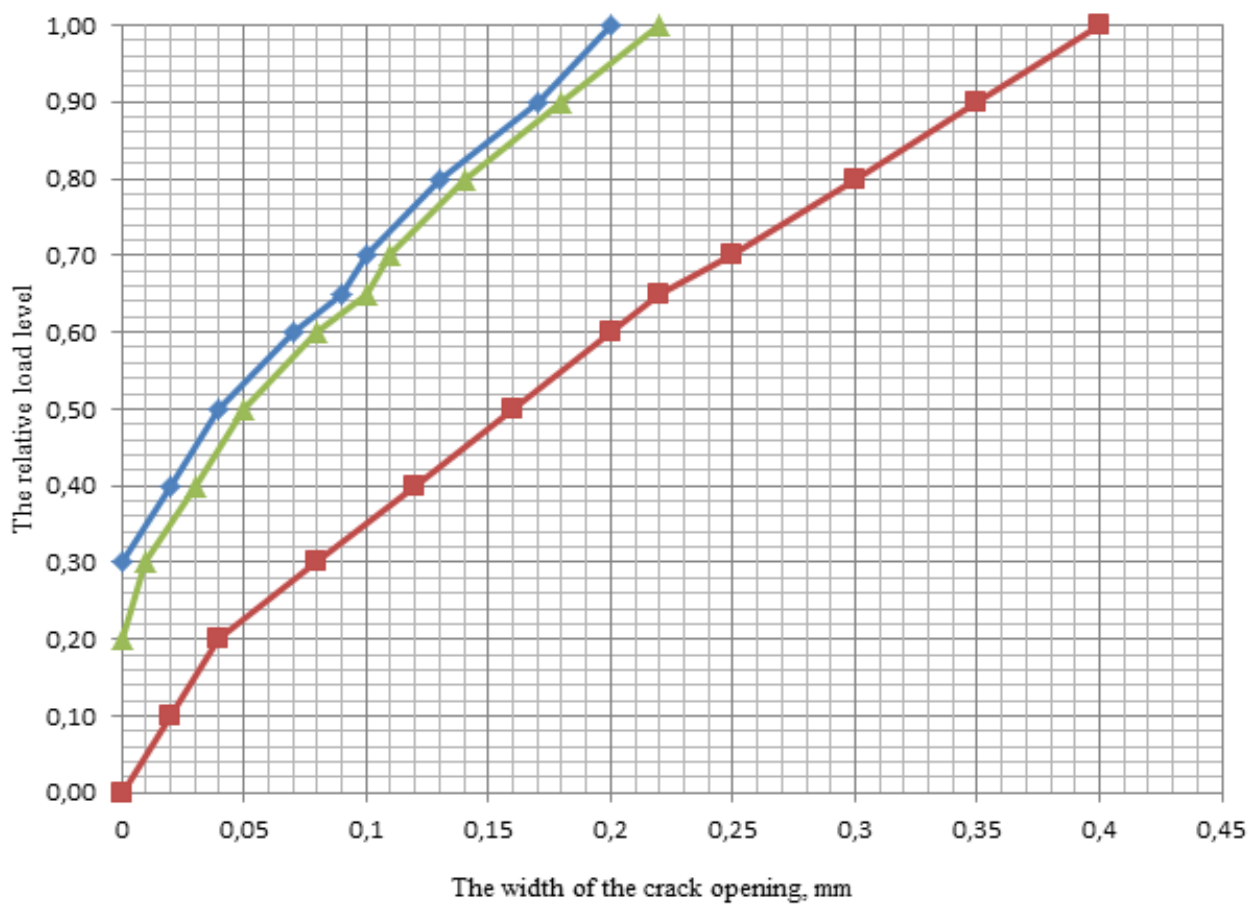

Fig. 13. The width of cracks in beams with the percentage of longitudinal reinforcement $\mu=3,35 \%$

On Fig. 9-13 blue line shows the crack opening width with respect to the relative load level for polymer concrete beams, red line - for concrete beams, green - for kauton reinforcement beams.

The width of cracks increased almost in proportion to the bending moments within the elastic reinforcement work. For beams, collapsing on the tension zone, the dependence of the width of the cracks from bending moments is close to linear.

Analysis of a graph of the width of the opening of normal cracks tested beams on the ratio of the relative load level also shows that the width of the opening of normal cracks of double-layered beams is largely dependent on the percentage of longitudinal reinforcement $\mu$. Normal opening width of cracks decreases with increasing percentage of the longitudinal reinforcement.

\section{Conclusions}

1. The normal cross section of two-layered polymer concrete of flexural members in the middle of the span undergoes three stages of stress-strain state.

2. The strength of the flexural members kauton reinforcement, polymer concrete and concrete increases with the percentage of longitudinal reinforcement. By increasing the percentage of longitudinal reinforcement from $0.84 \%$ to $3.35 \%$ the strength of normal sections of polymer concrete beams increases almost linearly.

3. The load bearing capacity of structures in the tension zone of polymer concrete is higher than that of reinforced concrete structures. High grip reinforcement and polymer concrete prevents rapid development of plastic deformation in the reinforcement, as well as part of polymer concrete on tension zone between the cracks involved in construction as a whole.

4. In a small percentage of reinforcement, polymer concrete beam collapse under the 
action of a higher load than in kauton reinforcement, but with an increased reinforcement, load bearing capacity of kauton reinforced elements becomes greater than polymer concrete by $5.4-6.5 \%$.

5. Crack resistance of polymer concrete samples is significantly higher than that of concrete (average 78.05\%). Crack resistance of polymer concrete samples is higher than kauton reinforcement (average 12.78\%), but a small percentage of longitudinal reinforcement $(\mu=0,84 \%)$ samples from kauton reinforcement showed the best evidence of crack resistance than polymer concrete (by $9.96 \%$ ).

6. The tests allowed the identification of three stages of the formation of cracks in the normal bilayer polymer concrete of flexural members of the T-sections.

7. With increasing percentage of longitudinal reinforcement, effect of raising the crack resistance decreases. This is due to the fact that in a high percentage of reinforcement, significant part of the force at the period of crack experienced reinforcement and only a small proportion of the load acted on polymer concrete.

8. The difference in the deformation of polymer concrete on tensile zone of two-layered beams and extensibility limit of corresponding polymer concrete control samples, averagely is $10 \%$. This is because high adhesion of polymer concrete with reinforcement increases the tensile limit of polymer concrete in constructions.

\section{References}

1. Yu.M. Borisov, Bulletin of the Central regional branch RAASN: collection of scientific articles. - Voronezh: VGASU, 133 - 137 (2010)

2. Yu.M. Borisov, Scientific Bulletin VGASU "Construction and architecture". Voronezh: VGASU, 18-24 (2010)

3. Yu.M. Borisov, Building mechanics and construction. - Voronezh: VGASU, 76 (2012)

4. Yu.M. Borisov, Scientific Israel - Technological Advantages, 14 (2), 11 (2012)

5. Yu.M. Borisov, Industrial and civil construction, 7, 47-49 (2010)

6. Yu.B. Potapov, Proceedings of the international scientific conference (IV Academic Reading RAASN) "Actual problems of building materials": Sat. scientific. Article. Penza, 16-17 (1998)

7. Yu.B. Potapov, Building Materials of the XXI century, 9, 9-10 (2000)

8. A.E. Polikutin, The strength and crack resistance of the inclined sections of the bent structural elements of kauton reinforcement, dis. ... Cand. tehn. Sciences: 05.23.01 (2002)

9. O.L. Figovsky, Eastern European Journal of advanced technologies, 6(11), $14-20$ (2014)

10. Nguyen Phan Duy Double-layered rubber concrete of bent elements of building structures, diss. ... Cand. tehn. Sciences: 05.23 .01 (2010)

11. Pinaev S.A. Short compressed elements of building constructions of an effective composite based on butadiene polymer [Text]: diss. ... Cand. tehn. Sciences: 05.23.01 / Pinaev Sergey. - Voronezh, 2001. - $191 \mathrm{p}$.

12. V.A. Chmykhov, The resistance of the rubber concrete to aggressive media, diss. ... Cand. tehn. Sciences: 05.23.05 (2002) 